\title{
In Situ Investigation of the Remineralizing Effect of Saliva and Fluoride on Enamel Following Prophylaxis Using Sodium Bicarbonate
}

\author{
Gladis Benjamina Grazziotina \\ Daniela Rios ${ }^{b}$ \\ Heitor Marques Honório ${ }^{b}$ \\ Salete Moura Bonifácio Silva ${ }^{b}$ \\ José Eduardo Oliveira Lima ${ }^{b}$
}

\section{ABSTRACT}

Objectives: This in situ study evaluated the effect of saliva, associated or not with fluoride, on enamel previously submitted to prophylaxis using sodium bicarbonate.

Methods: The study was conducted on enamel blocks submitted to in vitro prophylaxis using sodium bicarbonate. The blocks were randomly divided into 2 groups (G1/G2) and mounted on intraoral appliances wore by 10 volunteers. $G 1$ blocks were directly exposed to saliva in situ, while blocks in $\mathrm{G} 2$ were exposed to saliva with fluoride (rinsing with $0.2 \% \mathrm{NaF}$ solution during the initial minute). Enamel alterations were evaluated using surface microhardness and profilometry. Enamel hardness data were analyzed by ANOVA and Tukey tests and surface wear was evaluated using paired $t$ test $(P<.05)$.

Results: No significant differences were found between $G 1$ and $G 2$ for enamel hardness and wear. The wear after prophylaxis was not different from the wear after the in situ stage. Baseline mean values of enamel hardness, after prophylaxis and after the in situ stage were $340 \pm 16.6,329 \pm 35.7$ and $354 \pm 37.8$ for $G 1$ and $338 \pm 15.6,312 \pm 46.3$ and $340 \pm 21.8$ for $G 2$, respectively.

Conclusions: It was concluded that saliva alone exhibited a similar effect to saliva associated with fluoride; after $4 \mathrm{~h}$ of in situ remineralization, there was no recovery in height of the enamel structure that had been lost due to the application of sodium bicarbonate. (Eur J Dent 2011;5:40-46)

Key words: Dental prophylaxis; Saliva; Fluoride; Wear; Dental enamel.

a Department of Pediatric Dentistry, Santa Cruz do Sul University, Santa Cruz do Sul -RS, Brazil.

b Department of Pediatric Dentistry, Orthodontics and Public Health, Bauru School of Dentistry, USP University of São Paulo, Bauru-SP, Brazil.

- Corresponding author: Heitor Marques Honório Faculdade de Odontologia de Bauru-USP. Departamento de Odontopediatria, Ortodontia e Saúde Coletiva. Alameda Octávio Pinheiro Bizolla, 9-75 - Bauru- SP- Brasil, 17012-901.

Phone: + 5514 3235-8256

E-mail: heitorhonoriođusp.br

\section{INTRODUCTION}

Dental caries has been widely investigated for decades. ${ }^{1,2}$ Knowledge of the multifactorial etiology of caries concerning cariogenic diet, frequent ingestion of sucrose, and presence of dental biofilm on the dental surface of a susceptible host for a certain period of time encouraged investigations into preventive methods. ${ }^{2-4}$

Initially, classical studies demonstrated that dietary control with reduced ingestion of sucrose leads to a lower prevalence of dental caries. ${ }^{5,6} \mathrm{How}$ - 
ever, in reality, the establishment of this preventive measure is difficult, since it requires changes in dietary habits that consequently demand cultural changes and the need to make individuals realize the value of oral health, which rarely occurs.

The use of fluorides has also been widely employed in the last decades..$^{7-9}$ However, indiscriminate use of systemic fluoride can cause adverse effects, such as the occurrence of dental fluorosis. ${ }^{10}$ Therefore, other preventive measures are needed.

Greater emphasis has been given to biofilm control as a probable preventive measure against dental caries. ${ }^{11-15}$ Mechanical dental plaque removal may be achieved by self-control measures (toothbrushing and flossing) or by professional prophylaxis. It should be highlighted that selfcontrol measures are subject to the child's and his/her family's limitations in performing oral hygiene. Taking this into consideration, children have been submitted to preventive programs based on regular plaque control by professional prophylaxis, which aims to compensate for poor toothbrushing. ${ }^{11-16}$

When regularly performed, professional prophylaxis may significantly reduce the progression of dental caries. ${ }^{11-15}$ One method for performing this procedure is the use of sodium bicarbonate.

Investigations comparing the effectiveness of prophylaxis using sodium bicarbonate with that performed using rubber cup and pumice reveal that sodium bicarbonate removes dental plaque more effectively, especially in pit and fissure regions. ${ }^{16,17}$ Tooth wear could be a possible adverse effect of the regular use of sodium bicarbonate. Thus, several studies have been conducted to quantify the amount of tooth structure removed in each session of professional prophylaxis using sodium bicarbonate. ${ }^{18-20}$ In general, authors agree that sodium bicarbonate has a slight effect on intact enamel. ${ }^{18-20}$ However, these studies evaluated the dental surface immediately after the procedure, while doubts still remain concerning the protective capacity of the oral environment due to the presence of saliva and/or fluoride. Oral fluids may offer some protection, even when considering the loss of tooth structure by abrasion caused by the mechanical action of sodium bicarbonate under water pressure.

Saliva is rich in minerals and proteins, it is supersaturated with calcium and phosphate ions, and it lubricates the teeth. ${ }^{21}$ Thus, saliva acts against demineralization and may be able to recover the slight mineral loss of enamel caused by prophylaxis using sodium bicarbonate. Furthermore, fluoride can increase the rate of re-mineralization due to its mechanism of action. ${ }^{8,22}$ However, it is not known whether fluoride may influence the redeposition of minerals in case of abrasion of enamel surfaces.

Considering such aspects, this in situ study aimed to evaluate the effect of saliva, whether associated or not with fluoride, on enamel that had previously been subjected to prophylaxis using sodium bicarbonate.

\section{MATERIAL AND METHODS}

Experimental design

This in situ study involved a crossover, blind design performed in two phases of 4 hours, ${ }^{20}$ with a wash-out period of 7 days. The groups under study were: G1-treatment with sodium bicarbonate jet in vitro and saliva exposure for $4 \mathrm{~h}$ in situ, and $\mathrm{G} 2-$ treatment with sodium bicarbonate jet in vitro, $0.2 \%$ $\mathrm{NaF}$ rinse during the first minute and saliva exposure for $4 \mathrm{~h}$ in situ. Each phase corresponded to one group: G1 or G2. Ten healthy adult volunteers living in the same fluoridated area $(0.7 \mathrm{ppm})$ with a mean age of 28 years (range 23-35 years) and normal salivary flow rate took part in this study after signing an informed, written consent, approved by the IRB of Bauru Dental School, University of São Paulo. They wore acrylic palatal appliances, each containing two dental enamel blocks (Figure 1).

\section{Preparation of the enamel blocks}

Enamel blocks ( $4 \times 4 \times 3 \mathrm{~mm})$ were prepared from bovine incisors sterilized by storage in $2 \%$ formaldehyde solution $\mathrm{pH} 7.0$ for 30 days at room temperature. ${ }^{23}$ The enamel surface of the blocks was ground flat with water-cooled carborundum discs 1320,600 , and 1200 grits of Al203 papers; Buehler, Lake Bluff, IL, USA), and polished with diamond spray (1 $\mu \mathrm{m}$; Buehler).

Baseline superficial microhardness assessment

For surface enamel hardness determination, five indentations were done in different regions of the block (25 g, 5 s, HMV-2000; Shimadzu Corporation, Tokyo, Japan). The microhardness tester was 
calibrated before use and all measurements were conducted by the same person throughout the experiment. Forty blocks that had a mean hardness of approximately $339 \mathrm{KHN}$ were selected. These blocks were randomly assigned to the two groups and the baseline hardness values of the blocks were similar for both groups. Each group contained 20 enamel blocks (duplicates) or 10 experimental units $(n=10)$. These blocks were randomly assigned to the two groups.

In vitro sodium bicarbonate jet application

To maintain reference surfaces, two layers of nail varnish were applied on half of the blocks' surfaces. ${ }^{18-20}$ On the other half, the sodium bicabornate jet was applied (Dabi Atlante Industrias Médico Odontológicas LTDAl at a distance of 5 $\mathrm{mm}$ from the block for 10 seconds, at a $90^{\circ}$ angle, without interruption. ${ }^{18-20}$ After this procedure, the nail varnish was removed and the enamel hardness and profilometric analyses were conducted.

\section{Surface profilometry}

Enamel wear was determined by profilometry (Hommel Tester T1000, VS, Schwenningen).1,20-22 The tracing parameters were established at Lt: $1.5 \mathrm{~mm}$ and Lc: $0.25 \mathrm{~mm}$, and the profilometry accuracy is $0.4 \mu \mathrm{m}$. Four readings were performed on each block from the reference to the exposed surface. The average wear depth by volunteer of an experimental unit was computed using 8 readings, four each of two blocks.

\section{Superficial microhardness assessment}

After the profilometric measurements were made, the blocks were once again subjected to microhardness tests in the same manner as described above. The nail varnish was reapplied on half of the blocks' surfaces.

In situ saliva and fluoride effect

Ten days prior to the beginning of the experiment, and also during the whole experimental period, the volunteers brushed their teeth with fluoridated dentifrice (Colgate $\circledR$ - 1450 ppm of fluoride). Custom-made acrylic palatal devices were made with 2 cavities in the surface of each appliance. One block was fixed with wax in each of the 2 cavities. In $\mathrm{G} 1$, the volunteers wore the appliance inside the mouth for $4 \mathrm{~h}$. In $\mathrm{G} 2$, the volunteers also wore the appliance for $4 \mathrm{~h}$, but during the first minute, with the appliance in place, they rinsed using a $0.2 \% \mathrm{NaF}$ solution (Pharmácia Específica LTDA, Bauru, SP).

Profilometry measurements and superficial microhardness assessment

The nail varnish was removed and the microhardness and profilometry measurements were made as described above.

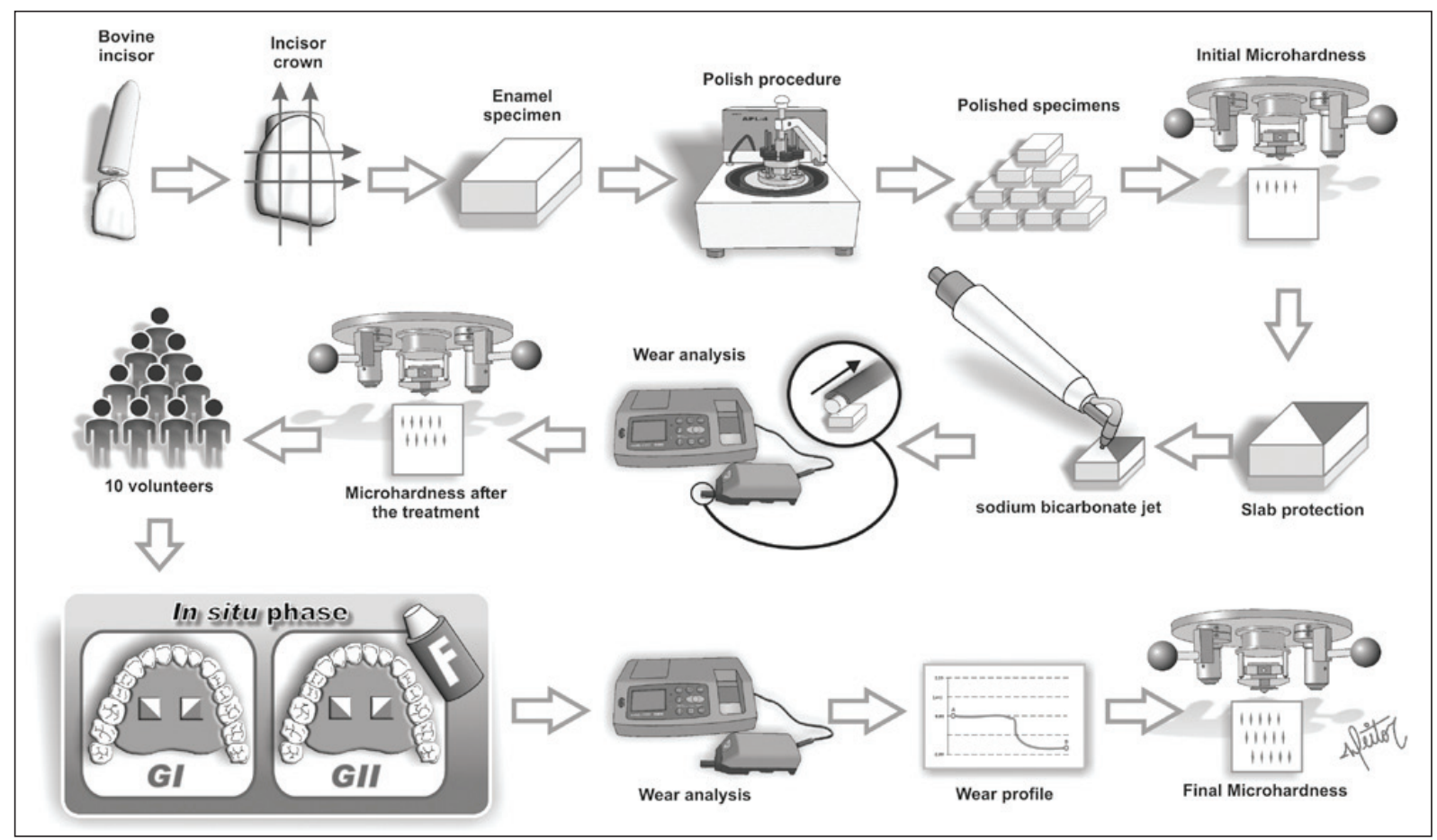

Figure 1. Schematic drawing of the experimental design. 


\section{Statistical analysis}

The assumptions of equality of variances and normal distribution of errors were checked for the response variables tested. Since the assumptions were satisfied, ANOVA and Tukey's tests were carried out for statistical comparisons for superficial enamel hardness data. A t-test was used to compare $\mathrm{G} 1$ and $\mathrm{G} 2$, taking into account the differences of final and baseline surface profiles (wear). For all tests, the significance level was set at $P \leq .05$.

\section{RESULTS}

Concerning the variable surface hardness, statistical analysis revealed no statistically significant difference in the action of saliva compared to saliva associated with fluoride (Table 1). Professional prophylaxis applied on enamel blocks in vitro led to statistically significantly lower surface hardness compared to baseline hardness values and after the in situ stage (Table 1).

With regard to wear, there was no significant difference between wear after prophylaxis compared to the in situ situation (Table 1). The wear of G1 was different from that found in G2; however, this difference was also observed between groups before the in situ stage (Table 1). Thus, the paired t test was applied to allow a more correct analysis $(P<.05)$, considering the results of differences in wear (profile after study in the in situ stage minus profile after prophylaxis), so that the initial differences would not be considered. The results reveal that the wear of blocks submitted to saliva $(-0.0016)$ was similar to the wear of blocks submitted to saliva associated with fluoride $(-0.0074)$ $(P=0.6196)$.

\section{DISCUSSION}

Most investigations of the wear caused by professional methods for dental plaque removal have an in vitro design18-20 and do not consider the protective properties of the oral environment, mainly related to the action of saliva. The in situ models suggested by Kolourides et $\mathrm{al}^{24}$ for investigations on dental caries present great advantages compared to laboratory studies. The in situ model may simulate intraoral events and simultaneously standardize the experimental conditions; at a short time period, they allow for the development of enamel alterations or recovery. ${ }^{25}$

Bovine incisors was used in this study because they have been widely used in dental research, ${ }^{26-28}$ especially because of their structural similarity to human tooth, ${ }^{29}$ homogeneous and reproducible surface, ${ }^{30}$ and lower biological variability, ${ }^{30}$ since they are not exposed to high concentrations of fluoride. . $4,25,28^{2}$

The 4-hour period for duration of each step was based on the findings of Ribeiro et al. ${ }^{20}$ These authors demonstrated that, after one hour in an in vitro study, saliva can recover previously abraded bovine enamel. Moreover, this period of time is the maximum mean period during which the oral cavity is not subjected to other stimuli after professional prophylaxis, such as contact with food. ${ }^{20}$

In the present study, after professional prophylaxis with sodium bicarbonate in vitro, there was a reduction in surface enamel hardness. Since this exposed surface was less mineralized, saliva had a remineralizing action, with a significant increase in surface hardness, which was not different from baseline hardness. Similar results were observed by Ribeiro et al, ${ }^{20}$ who conducted an in vitro study to investigate the action of saliva on enamel previously submitted to professional prophylaxis. They observed an increase in surface hardness after one hour.

Conversely, analysis of wear did not reveal any reparative action of saliva. After the in situ stage, during which the blocks were submitted to the ac-

Table 1. Mean and standard deviation (sd) of surface microhardness (KHN) and wear $(\mu \mathrm{m})$ of experimental groups, after initial selection, in the in vitro stage after prophylaxis and in the in situ stage.

\begin{tabular}{lccc}
\hline Response variable & $\begin{array}{c}\text { Initial selection } \\
\text { Initial - mean } \pm \text { sd }\end{array}$ & $\begin{array}{c}\text { In vitro phase } \\
\text { Prophy - mean } \pm \text { sd }\end{array}$ & $\begin{array}{c}\text { In situ phase } \\
\text { Final - mean } \pm \text { sd }\end{array}$ \\
\hline Microhardness G1 & $340.05 \pm 16.61^{\mathrm{a}, \mathrm{A}}$ & $329.50 \pm 35.68^{\mathrm{a}, \mathrm{B}}$ & $354.6 \pm 37.81^{\mathrm{a}, \mathrm{A}}$ \\
Microhardness G2 & $338.25 \pm 15.63^{\mathrm{a}, \mathrm{A}}$ & $312.35 \pm 46.30^{\mathrm{a}, \mathrm{B}}$ & $340.15 \pm 21.76^{\mathrm{a}, \mathrm{A}}$ \\
Wear G1 & - & $0.495 \pm 0.176^{\mathrm{a}, \mathrm{A}}$ & $0.493 \pm 0.181^{\mathrm{a}, \mathrm{A}}$ \\
Wear G2 & & $0.312 \pm 0.157^{\mathrm{b}, \mathrm{A}}$ & $0.319 \pm 0.160^{\mathrm{b}, \mathrm{A}}$ \\
\hline
\end{tabular}

*: Values in the same column followed by different lower case letters and in the same line followed by capital letters are statistically significant $(P<.05)$. 
tion of saliva for 4 hours, there was no significant reduction in wear. On the other hand, during investigations on demineralized enamel by artificial caries solution, the author $\mathrm{s}^{20}$ observed reduction in wear, in agreement with Honório et al. ${ }^{18}$ These results may be explained by the fact that the enamel with white spot lesions is especially more prone to chemically receiving minerals (calcium and phosphate) from saliva, since the enamel crystals are altered and consequently have lower mineral content, which are still present in the tooth structure, thus allowing recovery and a slight gain in height. ${ }^{36}$ Conversely, sound enamel submitted to mechanical wear completely loses the surface crystals, precluding recovery and structure gain in height, since there is no matrix for deposition of ions from the saliva.

In the present study, care was taken to assure the homogeneity of experimental groups by random division according to initial surface enamel hardness. Notwithstanding, G1 exhibited statistically higher wear than $\mathrm{G} 2$ after in vitro professional prophylaxis, which was performed equally for both groups, even though hardness values after prophylaxis were not different between the groups. There is no explanation for such an outcome; however, to overcome this problem, the difference in wear should be considered to allow actual comparison of influence of the in situ stage between G1 and G2.

The action of fluoride on a structure previously submitted to professional prophylaxis was investigated because no studies have addressed its effect on exclusively abraded surfaces, even though the remineralizing effect of this element on surfaces previously demineralized by dental caries is well established. The $0.2 \% \mathrm{NaF}$ solution was selected due to the demonstrated clinical action for caries remineralization and easy utilization. ${ }^{32,33}$ A solution was employed because utilization of dentifrice might promote further wear, since its utilization is related to toothbrushing (abrasion).

The results revealed that the action of saliva (G1) was not different from saliva associated with $0.2 \%$ sodium fluoride (G2) for both surface enamel hardness and wear variables. Both promoted an increase in surface enamel hardness 1 G1, 329 and $354 \mathrm{KHN} ; \mathrm{G} 2,312$ and 340 after prophylaxis and after the in situ stage, respectively), yet none could reestablish the enamel in height IG1 -0.0016 and G2 -0.0074 of mean difference).
Initially, it was assumed that utilization of fluoridated dentifrice before the in situ stage might promote a residual effect of fluoride, thus masking the effect of fluoride mouth rinse. This phenomenon hardly occurred, since care was taken to assure a one-hour interval between toothbrushing and onset of the in situ stage, to avoid the action of fluoride from dentifrice in the study. ${ }^{34}$ However, Bruun, Givskov, and Thylstrup ${ }^{35}$ found residual fluoride in saliva for more than one hour after toothbrushing with fluoridated dentifrice, compared to saliva of the placebo dentifrice. Thus, future studies should ideally evaluate the fluoride in saliva before onset of the in situ stage, increase the washout period of dentifrice, or employ non-fluoridated dentifrice.

The type of fluoride may also influence the outcome. High concentration fluorides, such as fluoridated varnishes, have demonstrated greater effectiveness in remineralization. ${ }^{36}$ In addition, some authors ${ }^{37,38}$ observed that concentrations above 500 ppm of fluoride did not produce significant increase in remineralization. Similar studies should be conducted to compare several concentrations of fluoride to promote $r$ a better understanding of the action of fluoride on abrasion. Moreover, its action should be evaluated not only on "intact" enamel, but also on previously demineralized enamel.

Thus, considering the importance of mechanical biofilm removal as a caries preventive measure, regardless of the effectiveness of the in situ action of saliva associated or not with fluoride to recover the enamel structure lost during prophylaxis with sodium bicarbonate, the wear produced by this procedure was very slight. Therefore, professionals may safely perform prophylaxis without concern regarding the adverse effects of significant loss of intact tooth structure. In the case of high caries risk patients who present dental plaque accumulation, high concentration topical fluoride products may be professionally applied after prophylaxis, enhancing remineralization.

\section{CONCLUSIONS}

Based on the results, it was concluded that saliva exhibited a similar effect as saliva associated with fluoride; after $4 \mathrm{~h}$ of in situ remineralization, there was no recovery in height of the tooth structure lost due to application of sodium bicarbonate on sound enamel. 


\section{ACKNOWLEDGMENTS}

The authors would like to gratefully acknowledge Prof. Dr. José Roberto Pereira Lauris for the statistical analysis.

\section{REFERENCES}

1. Honório HM, Rios D, Santos CF, Magalhães AC, Buzalaf MA, Machado MA. Effects of erosive, cariogenic or combined erosive/cariogenic challenges on human enamel: an in situ/ex vivo study. Caries Res 2008;42:454-459.

2. Keyes PH. The infectious and transmissible nature of experimental dental caries. Findings and implications. Arch Oral Biol 1960;1:304-320.

3. Kidd EA, Fejerskov 0. What constitutes dental caries? Histopathology of carious enamel and dentin related to the action of cariogenic biofilms. J Dent Res 2004;83:C35-C38.

4. Takahashi N, Nyvad B. Caries ecology revisited: microbial dynamics and the caries process. Caries Res 2008;42:409418.

5. Gustafsson BE, Quensel CE, Lanke LS, Lundqvist C, Grahnen $\mathrm{H}$, Bonow $\mathrm{BE}$, Krasse $\mathrm{B}$. The Vipeholm dental caries study; the effect of different levels of carbohydrate intake on caries activity in 436 individuals observed for five years. Acta Odontol Scand 1954;11:232-264.

6. Harris R. Biology of the children of hopewood house, bowral, australia. 4. Observations on dental-caries experience extending over five years (1957-61). J Dent Res 1963;42:1387-1399

7. Ccahuana-Vásquez RA, Tabchoury CP, Tenuta LM, Del Bel Cury AA, Vale GC, Cury JA. Effect of frequency of sucrose exposure on dental biofilm composition and enamel demineralization in the presence of fluoride. Caries Res 2007:41:9-15

8. Hellwig E, Lussi A. What is the optimum fluoride concentration needed for the remineralization process? Caries Res 2001;35:57-59.

9. Paes-Leme A, Dalcico R, Tabchoury C, Del Bel Cury A, Rosalen P, Cury J. In situ effect of frequent sucrose exposure on enamel demineralization and on plaque composition after APF application and F dentifrice use. J Dent Res 2004;83:71-75.

10. Fejerskov 0, Manji F, Baelum V. The nature and mechanisms of dental fluorosis in man. $J$ Dent Res 1990;69:692700.

11. Axelsson P, Lindhe J, Nystrom B. On the prevention of caries and periodontal disease. Results of a 15-year longitudinal study in adults. J Clin Periodontol 1991;18:182-189.

12. Axelsson $P$, Lindhe J, Waseby J. The effect of various plaque control measures on gingivitis and caries in schoolchildren. Community Dent Oral Epidemiol 1976;4:232-239.
13. Axelsson P, Lindhe J. Effect of oral hygiene instruction and professional toothcleaning on caries and gingivitis in schoolchildren. Community Dent Oral Epidemiol 1981;9:251255

14. Axelsson P, Lindhe J. The effect of a preventive programme on dental plaque, gingivitis and caries in schoolchildren. Results after one and two years. J Clin Periodontol 1974;1:126-138

15. Holmen L, Mejare I, Malmgren B, Thylstrup A. The effect of regular professional plaque removal on dental caries in vivo. A polarized light and scanning electron microscope study. Caries Res 1988;22:250-256.

16. Strand GV, Raadal M. The efficiency of cleaning fissures with an air-polishing instrument. Acta Odontol Scand 1988;46:113-117.

17. Weaks LM, Lescher NB, Barnes CM, Holroyd SV. Clinical evaluation of the Prophy-Jet as an instrument for routine removal of tooth stain and plaque. $J$ Periodontol 1984;55:486-488

18. Honório HM, Rios D, Abdo RCC, Machado MAAM. Effect of different prophylaxis methods on sound and demineralized enamel. J Appl Oral Sci 2006;14:117-123.

19. Hosoya Y, Johnston JW. Evaluation of various cleaning and polishing methods on primary enamel. $J$ Pedod 1989;13:253-269

20. Ribeiro HZV, Lima JEO, Vono BG, Machado MAAM, Silva SMB. Airpolishing effect on bovine enamel and the posterior remineralizing effect of saliva. An in vitro study. J Appl Oral Sci 2006;14:193-197.

21. Mandel ID. The functions of saliva. J Dent Res 1987;66:623627.

22. Llena C, Forner L, Baca P. Anticariogenicity of casein phosphopeptide-amorphous calcium phosphate: a review of the literature. J Contemp Dent Pract 2009;10:1-9.

23. Magalhães AC, Rios D, Honório HM, Jorge AM Jr, Delbem AC, Buzalaf MA. Effect of $4 \%$ titanium tetrafluoride solution on dental erosion by a soft drink: an in situ/ex vivo study. Arch Oral Biol 2008;53:399-404.

24. Koulourides T, Chien MC. The ICT in situ experimental model in dental research. J Dent Res 1992;71:822-827.

25. Zero DT. In situ caries models. Adv Dent Res 1995;9:214230.

26. Amaechi BT, Higham SM, Edgar WM. Factors affecting the development of carious lesions in bovine teeth in vitro. Arch Oral Biol 1998;43:619-628.

27. Featherstone JD, Mellberg JR. Relative rates of progress of artificial carious lesions in bovine, ovine and human enamel. Caries Res 1981:15:109-114. 
28. Mellberg JR. Hard-tissue substrates for evaluation of cariogenic and anti-cariogenic activity in situ. J Dent Res 1992; 71:913-919.

29. Sato I, Sunohara M, Mikami A, Yoshida S, Sato T. Comparison between deciduous and permanent incisor teeth in morphology of bovine enamel. Okajimas Folia Anat Jpn 1999;76:131-135.

30. Manning RH, Edgar WM. Intra-oral models for studying deand remineralization in man: methodology and measurement. J Dent Res 1992;71:895-900.

31. Arends J, Christoffersen J. Nature and role of loosely bound fluoride in dental caries. J Dent Res 1990;69:601-605.

32. Ogaard B, Rolla G, Dijkman T, Ruben J, Arends J. Effect of fluoride mouthrinsing on caries lesion development in shark enamel: an in situ caries model study. Scand J Dent Res 1991;99:372-377.

33. Ogaard B, Rolla G, Helgeland K. Uptake and retention of alkali-solube and alkali-insoluble fluoride in sound enamel in vivo after mouthrinses with $0.05 \%$ or $0.2 \% \mathrm{NaF}$. Caries Res 1983; 17:520-524.

34. Bruun C, Lambrou D, Larsen MJ, Fejerskov 0, Thylstrup A. Fluoride in mixed human saliva after different topical fluoride treatments and possible relation to caries inhibition. Community Dent Oral Epidemiol 1982;10:124-129.

35. Bruun C, Givskov H, Thylstrup A. Whole saliva fluoride after toothbrushing with $\mathrm{NaF}$ and MFP dentifrice with different $\mathrm{F}$ concentrations. Caries Res 1984;18:282-288.

36. Eakle WS, Featherstone JD, Weintraub JA, Shain SG, Gansky SA. Salivary fluoride levels following application of fluoride varnish or fluoride rinse. Community Dent Oral Epidemiol 2004;32:462-469.

37. Cruz R, Ogaard B, Rolla G. Uptake of $\mathrm{KOH}$-soluble and $\mathrm{KOH}$-insoluble fluoride in sound human enamel after topical application of a fluoride varnish (Duraphat) or a neutral $2 \% \mathrm{NaF}$ solution in vitro. Scand J Dent Res 1992;100:154-158.

38. Damato FA, Strang R, Stephen KW. Effect of fluoride concentration on remineralization of carious enamel: an in vitro ph-cycling study. Caries Res 1990;24:174-180. 